\title{
Myxomycetes of Stewart Island, New Zealand
}

\section{Stephenson $\mathrm{SL}^{{ }^{*}}$, Stephenson $\mathrm{BC}^{2}$ and Stephenson $\mathrm{RJ}^{3}$}

\author{
${ }^{1}$ Department of Biological Sciences, University of Arkansas, Fayetteville, Arkansas 72701, slsteph@uark.edu \\ ${ }^{2}$ Department of Mathematics, University of Arkansas, Fayetteville, Arkansasa 72701, bcsteph@uark.edu \\ ${ }^{3}$ Admiral Robert E. Byrd Middle School, 134 Rosa Lane, Winchester, Virginia 22602, stephens00@sbc.edu
}

Stephenson SL, Stephenson BC, Stephenson RJ 2012 - Myxomycetes of Stewart Island, New Zealand. Mycosphere 3(6), 940-947, Doi 10.5943 /mycosphere/3/6/8

Records of myxomycetes obtained as a result of field surveys carried out on Stewart Island in February and April of 1998 were supplemented with records of species appearing in moist chamber culture on samples of various types of dead plant material collected during the field surveys and a small set of samples collected in 2006. In addition, previously published records and all known herbarium records of these organisms were compiled in an effort to produce a comprehensive checklist of the myxomycetes for this region of New Zealand. The assemblage of 51 species reported from Stewart Island is more diverse than that of any of the subantarctic islands or island groups (Macquarie, Campbell, Auckland and Snares) but is much less diverse than mainland New Zealand.

Key words - ecology - island biogeography - slime molds

\section{Article Information}

Received 25 October 2012

Accepted 29 October 2012

Published online 23 November 2012

*Corresponding author: Steven L. Stephenson - e-mail - slsteph@uark.edu

\section{Introduction}

The myxomycetes (plasmodial slime molds or myxogastrids) are a group of funguslike organisms usually present and sometimes abundant in terrestrial ecosystems (Martin \& Alexopoulos 1969). Approximately 900 species are currently known (Lado 20052010). The reproductive, or spore-producing, stage in the myxomycete life cycle can achieve macroscopic dimensions and be collected and preserved for study in much the same way as the sporocarps of fungi. However, most species of myxomycetes tend to be rather inconspicuous or sporadic in their occurrence and thus not always easy to detect in the field. Moreover, fruiting bodies of most species are relatively ephemeral and do not persist in nature for very long. Because of their life history strategy and inconspicuous nature, myxomycetes provide an immense challenge in biodiversity assessments and, consequently, often have been neglected in such studies. The present paper represents an effort to document all of the species of myxomycetes reported from or known to occur on Stewart Island, where few studies of these organisms have ever been carried out.

The first individual to collect myxomycetes on Stewart Island appears to have been a Miss Hibbert-Ware in 1904, as reported by Lister \& Lister (1905). HibbertWare recorded a total of 20 species, including one species (Physarum dictyospermum Lister \& G. Lister) new to science. Mitchell (1992), who compiled a checklist of the myxomycetes of New Zealand, mentioned these same species along with one additional record based on a herbarium specimen. In his monograph on the myxomycetes of New Zealand, Stephenson (2003) reported a total of 188 species for the entire country, including a number of new records for Stewart Island. In a later paper, 
Stephenson et al. (2009) increased this number to 196 , including one species new to science, but none of these additions were from Stewart Island.

\section{General Study Area}

Stewart Island is the southernmost and smallest (with a total land area of only 1746 $\mathrm{km}^{2}$ ) of the three main islands of New Zealand. Located at approximately $47^{\circ} 00^{\prime} \mathrm{S}$ latitude and $167^{\circ} 50^{\prime}$ E longitude, Stewart Island is characterized by a varied topography that ranges from an extensive wetland in the valley of the Freshwater River to rolling hills and mountain ridges that reach a maximum elevation of $979 \mathrm{~m}$ on the summit of Mount Anglem. The climate of the island is generally cool, moist and windy, with an annual precipitation that can exceed $3,000 \mathrm{~mm}$ in some localities. Forests dominated by podocarps and various species of broadleaf trees cover most of the island (Wilson 1994), with Nothofagus surprisingly absent.

\section{Materials and Methods}

Field surveys for myxomycetes were carried out at various localities on Stewart Island during February and April of 1998. Specimens of myxomycetes that had fruited in the field under nature conditions were collected. In addition, samples of dead plant material (forest floor litter, aerial litter and bark from living trees) were obtained at a number of localities. A few additional samples were collected in 2006 and sent to the University of Arkansas. All samples were used to prepare moist chamber cultures in the manner described by Stephenson \& Stempen (1994). Moist chambers consisted of disposable plastic Petri dishes (100 mm diameter) lined with filter paper. The sample material in each dish was moistened with distilled water. After a period of approximately 24 hours, excess water in each dish was removed. Cultures were kept at room temperature $\left(22-25^{\circ} \mathrm{C}\right)$ in diffuse daylight and examined with a stereomicroscope on a regular basis for a period of up to two months in order to detect plasmodia and/or fruiting bodies. When necessary, a small amount of water was added to each culture to maintain moist conditions. Myxomycete plasmodia and/or fruiting bodies were noted and recorded each time the cultures were checked, and all fruiting bodies were removed, air-dried and glued in small pasteboard boxes for permanent storage. Such collections are indicated by ' $\mathrm{mc}$ ' in the following list.

\section{Annotated List of Species}

In the list that follows, myxomycetes recorded from Stewart Island are arranged alphabetically by genus and then species. Information is provided on the source(s) of each record, along with comments on particularly noteworthy examples. The number of collections obtained in the study reported herein is given in parentheses. Nomenclature essentially follows Lado (2005-2010) except for Stemonitis nigrescens, where the treatment used is that of Martin \& Alexopoulos (1969). The abbreviation 'cf.' in the name of a species indicates that the specimen representing the source of the record could not be identified with certainty. This usually indicates scanty or aberrant material. Vouchers of all species reported herein were deposited in the herbaria of the University of Arkansas (UARK) or the New Zealand Fungi and Plant Disease Collection, Auckland (Herb. PDD). Except where indicated otherwise, collection numbers are those of the senior author (SLS).

Arcyria cinerea (Bull.) Pers. (9 collections)

Reported from Stewart Island by Stephenson (2003), based on a collections obtained in 1998.

Collection examined - roadside near Halfmoon Bay, aerial litter (mc), sample collected February 1998, SLS 9485 [PDD 68671].

Arcyria denudata (L.) Wettst. (1 collection) Island.

Not reported previously from Stewart

Collection examined - track to Deep Bay, podocarp-broadleaf forest, decaying wood, 29 April 1998, SLS 9608.

Arcyria incarnata (Pers. ex J.F. Gmel.) Pers. (5 collections)

First reported from Stewart Island by Lister \& Lister (1905), based on a collection made by Hibbert-Ware.

Collection examined - Ulva Island, 
podocarp-broadleaf forest, decaying wood, 9 February 1998, SLS 9227.

Arcyria obvelata (Oeder) Onsberg (2 collections)

Reported from Stewart Island by Stephenson (2003), based on a collection obtained in 1998.

Collection examined - Mount Anglem track, podocarp forest, decaying wood, 12 February 1998, SLS 9279 [PDD 68475].

Arcyria pomiformis (Leers) Rostaf. (4 collections) Island.

Not reported previously from Stewart

Collection examined - Ulva Island, podocarp-broadleaf forest, ground litter (mc), sample collected February 1998, SLS 10831.

Arcyria stipata (Schwein.) Lister (1 collection) Island.

Not reported previously from Stewart

Collection examined - Ulva Island, podocarp-broadleaf forest, decaying wood, 9 February 1998, SLS 9226.

Ceratiomyxa fruticulosa (O.F. Müll.) T. Macbr. (7 collections)

First reported (as Ceratiomyxa mucida (Pers.) J. Schröt.) from Stewart Island by Lister \& Lister (1905), based on a collection made by Hibbert-Ware.

Collection examined - Raroa Forest Reserve, podocarp forest, decaying wood, 12 February 1998, SLS 9274.

Clastoderma debaryanum A. Blytt (2 collections)

Reported from Stewart Island by Stephenson (2003), based on a collection obtained in 1998.

Collection examined - Raroa Forest Reserve, podocarp forest, decaying wood, 30 April 1998, SLS 9234 [PDD 88479].

Comatricha nigra (Pers. ex J.F. Gmel.) J. Schröt.

Reported from Stewart Island by Mitchell (1992), based on a collection in the herbarium of California State University
(Chico, California). This collection was obtained by B. Stagg in October 1981.

Craterium minutum (Leers) Fr.

First reported (as Craterium pedunculatum Trentep.) from Stewart Island by Lister \& Lister (1905), based on a collection made by Hibbert-Ware. This species was not encountered during our surveys.

Cribraria argillacea (Pers. ex. J.F. Gmel.) Pers. (1 collection)

Collection examined - track to Deep Bay, podocarp-broadleaf forest, decaying wood, 29 April 1998, SLS 9609.

Cribraria aurantiaca Schrad.

First reported from Stewart Island by Lister \& Lister (1905), based on a collection made by Hibbert-Ware. This species was not encountered during our surveys.

Cribraria cancellata (Batsch) Nann.-Bremek. (1 collection) Island.

Not reported previously from Stewart

Collection examined - track to Deep Bay, podocarp-broadleaf forest, decaying wood, 29 April 1998, SLS 9609.

Cribraria macrocarpa Schrad. (2 collections)

Reported from Stewart Island by Stephenson (2003), based on a collection obtained in 1998.

Collection examined - Raroa Forest Reserve, podocarp forest, decaying wood, 29 April 1998, SLS 9616 [PDD 68795].

Cribraria microcarpa (Schrad.) Pers. (3 collection) Island.

Not reported previously from Stewart

Collection examined - Ulva Island, podocarp-broadleaf forest, ground litter, 30 April 1998, SLS 22517.

Cribraria cf. vulgaris Schrad. (4 collections)

Not reported previously from Stewart Island.

Collection examined - track to Deep Bay, podocarp-broadleaf forest, decaying wood, 29 April 1998, SLS 9612. This species 
was represented by four collections, but all of these consist of old and somewhat poorly developed material. Although they key out to Cribraria vulgaris, it is possible that another species may be involved. However, whatever the species, it is clearly distinct from any other member of the genus recorded from Stewart Island.

Diachea leucopodia (Bull.) Rostaf.

Reported from Stewart Island by Mitchell (1992), based on a collection in PDD. This collection was obtained by J.M. Dingley at Horseshoe Bay in February 1954. This species was not encountered during our surveys.

Diderma cf. donkii Nann.-Bremek. (1 collection)

Not reported previously from Stewart Island.

Collection examined - Ulva Island, podocarp-broadleaf forest, dead leaves, 30 April 1998, SLS 9635. This is a problematic collection that could not be referred with certainty to any species of Diderma, although clearly a member of this genus. It appears to fit the concept of $D$. donkii more closely than any other species of Diderma with which the senior author is familiar.

Didymium melanospermum (Pers.) T. Macbr.

First reported (as Didymium farinaceum Schrad.) from Stewart Island by Lister \& Lister (1905), based on a collection made by HibbertWare. This species was not encountered during our surveys.

Didymium squamulosum (Alb. \& Schwein.) Fr. (4 collections)

First reported (as Didymium effusum Link) from Stewart Island by Lister \& Lister (1905), based on a collection made by HibbertWare.

Collection examined - roadside near Halfmoon Bay, aerial litter (mc), sample collected February 1998, SLS 9478 [PDD 68578].

Echinostelium minutum de Bary (11 collections)

Reported from Stewart Island by
Stephenson (2003), based on a collection obtained in 1998.

Collection examined - Metrosideros umbellata forest near Halfmoon Bay, bark (mc), sample obtained in February 1998, D. W. Mitchell 5443 [PDD 77057].

Enerthenema papillatum (Pers.) Rostaf. (1 collection)

Reported from Stewart Island by Stephenson (2003), based on a collection obtained in 1998.

Collection examined - Ulva Island, podocarp-broadleaf forest, dead bark, 30 April 1998, SLS 10822.

Fuligo cinerea (Schwein.) Morgan (1 collection)

Not reported previously from Stewart Island.

Collection examined - Raroa Forest Reserve, podocarp forest, decaying wood, 10 February 1998, SLS 22347.

Fuligo septica (L.) F.H. Wigg. (1 collection) Island.

Not reported previously from Stewart

Collection examined - Raroa Forest Reserve, podocarp forest, decaying wood, 10 February 1998, SLS 9253.

Hemitrichia calyculata (Speg.) M.L. Farr (1 collection)

Reported from Stewart Island by Stephenson (2003), based on a collection obtained in 1998.

Collection examined - Raroa Forest Reserve, podocarp forest, decaying wood, 9 February 1998, SLS 9210 [PDD 68483].

Hemitrichia leiocarpa (Cooke) Lister (3 collections) Island.

Not reported previously from Stewart

Collection examined - Halfmoon Bay, podocarp-broadleaf forest, bark (mc), sample collected February 1998, SLS 19825.

Licea operculata (Wingate) G.W. Martin (2 collections) Island.

Not reported previously from Stewart 
Collection examined - Ulva Island, podocarp-broadleaf forest, ground litter (mc), sample collected February 1998, SLS 10894.

Lycogala epidendrum (L.) Fr. (9 collections)

First reported (as Lycogala miniatum Pers.) from Stewart Island by Lister \& Lister (1905), based on a collection made by HibbertWare.

Collection examined - Raroa Forest Reserve, podocarp forest, decaying wood, 9 February 1998, SLS 9218.

Metatrichia floriformis (Schwein.) Nann.Bremek. (7 collections)

First reported from Stewart Island (as Trichia botrytis var. lateritia (Lév.) Lister) by Lister \& Lister (1905), based on a collection made by Hibbert-Ware.

Collection examined - Raroa Forest Reserve, podocarp forest, decaying wood, 11 February 1998, SLS 9264 [PDD 68486].

Perichaena chrysosperma (Curr.) Lister (1 collection)

Not reported previously from Stewart Island.

Collection examined - Mason Bay, beach dune community, aerial litter (mc), sample collected in February 1998, SLS 9391.

Perichaena vermicularis (Schwein.) Rostaf. (1 collection) Island.

Not reported previously from Stewart

Collections examined - Mason Bay, beach dune community, aerial litter (mc), sample collected February 1998, SLS 9392.

Physarum album (Bull.) Chevall. (2 collections)

First reported (as Physarum nutans Pers.) from Stewart Island by Lister \& Lister (1905), based on a collection made by HibbertWare.

Collection examined - track to Deep Bay, podocarp forest, dead bark, 29 April 1998, SLS 9613 [PDD 68740].

Physarum bivalve Pers. (2 collections) Island.
Collection examined - Ulva Island, podocarp-broadleaf forest, forest floor litter, 10 February 1998, SLS 9231.

Physarum cinereum (Batsch) Pers.

First reported from Stewart Island by Lister \& Lister (1905), based on a collection made by Hibbert-Ware. This species was not encountered during our surveys.

Physarum dictyospermum Lister \& G. Lister

This species was described as new to science by Lister \& Lister (1905) on the basis of material that Hibbert-Ware had collected on Stewart Island. It was not encountered during our surveys.

Physarum flavicomum Berk. (6 collections)

First reported (as Physarum berkeleyi Rostaf.) from Stewart Island by Lister \& Lister (1905), based on a collection made by HibbertWare.

Collection examined - Ulva Island, podocarp-broadleaf forest, decaying wood, 10 February 1998, SLS 9235.

Physarum globuliferum (Bull.) Pers. (7 collections)

First reported from Stewart Island by Lister \& Lister (1905), based on a collection made by Hibbert-Ware.

Collection examined - Raroa Forest Reserve, podocarp forest, decaying wood, 11 February 1998, SLS 9262 [PDD 77059].

Physarum lateritium (Berk. \& Ravenel) Morgan (1 collection)

Not reported previously from Stewart Island.

Collection examined - Raroa Forest Reserve, podocarp forest, decaying wood, 9 February 1998, SLS 9222.

Physarum pusillum (Berk. \& M.A. Curtis) G. Lister (3 collections)

First reported (as Physarum calidris Lister) from Stewart Island by Lister \& Lister (1905), based on a collection made by HibbertWare.

Collection examined - Mason Bay, beach dune community, aerial litter (mc), sample collected February 1998, SLS 9390. 
Physarum viride (Bull.) Pers. (4 collections)

First reported from Stewart Island by Lister \& Lister (1905), based on a collection made by Hibbert-Ware.

Collection examined - Ulva Island, podocarp-broadleaf forest, decaying wood, 9 February 1998, SLS 9216 [PDD 68587].

Stemonitis axifera (Bull.) T. Macbr. (6 collections)

First reported (as Stemonitis ferruginea Ehrenb.) from Stewart Island by Lister \& Lister (1905), based on a collection made by HibbertWare.

Collection examined - Halfmoon Bay, podocarp-broadleaf forest, decaying wood, 9 February 1998, SLS 9213.

\section{Stemonitis fusca Roth}

First reported Stewart Island by Lister \& Lister (1905), based on a collection made by Hibbert-Ware. This species was not encountered during our surveys.

Stemonitis nigrescens Rex. (11 collections)

Not reported previously from Stewart Island. As noted earlier, Lado did not recognize Stemonitis nigrescens as distinct from $S$. fusca, although the ecological distribution of the two taxonomic entities is consistently different (Ing 1999).

Collection examined - Raroa Forest Reserve, podocarp forest, ground litter (mc), sample collected March 1998, SLS 10357.

Stemonitis splendens Rostaf. (3 collections)

Not reported previously from Stewart Island.

Collection examined - Raroa Forest Reserve, podocarp forest, dead bark, 10 February 1998, SLS 9250.

Stemonitopsis typhina (F.H. Wigg.) Nann.Bremek. (10 collections)

First reported (as Comatricha typhoides [Bull.] Rostaf. ex Lister) from Stewart Island by Lister \& Lister (1905), based on a collection made by Hibbert-Ware.

Collection examined - Raroa Forest Reserve, podocarp forest, decaying wood, 11 February 1998, SLS 9265 [PDD 68491].
Trichia botrytis (J.F. Gmel.) Pers.

First reported from Stewart Island by Lister \& Lister (1905), based on a collection made by Hibbert-Ware. This species was not encountered in our surveys.

Trichia decipiens (Pers.) T. Macbr. (5 collections)

First reported (as Trichia fallax Pers.) from Stewart Island by Lister \& Lister (1905), based on a collection made by Hibbert-Ware,

Collection examined - Raroa Forest Reserve, podocarp forest, decaying wood, 9 February 1998, SLS 9219.

\section{Trichia favoginea (Batsch) Pers.}

First reported (as Trichia affinis de Bary) from Stewart Island by Lister \& Lister (1905), based on a collection made by HibbertWare. This species was not encountered in our surveys.

Trichia persimilis $\mathrm{P}$. Karst.

First reported from Stewart Island by Lister \& Lister (1905), based on a collection made by Hibbert-Ware. This species is not always recognized as distinct from Trichia favoginea.

Trichia verrucosa Berk. (11 collections)

First reported from Stewart Island by Lister \& Lister (1905), based on a collection made by Hibbert-Ware.

Collection examined - Halfmoon Bay, podocarp forest, decaying wood, 29 April 1998, SLS 9619 [PDD68767].

Tubifera ferruginosa (Batsch) J.F. Gmel. (1 collection)

Reported from Stewart Island by Stephenson (2003), based on a collection obtained in 1998.

Collection examined - Ulva Island, podocarp-broadleaf forest, decaying wood, 10 February 1998, SLS 9238 [PDD 68586].

\section{Discussion}

The 17 species reported herein as new records for Stewart Island bring the total number of species of myxomycetes known from the island to 51. This represents 
Table 1 Numbers of collections and species recorded from Stewart Island and the New Zealand subantarctic islands or island groups.

\begin{tabular}{lcccl}
\hline $\begin{array}{l}\text { Island or } \\
\text { island group }\end{array}$ & $\begin{array}{l}\text { Approximate } \\
\text { latitude }\end{array}$ & $\begin{array}{c}\text { Number of } \\
\text { collections }\end{array}$ & $\begin{array}{c}\text { Number of } \\
\text { species }\end{array}$ & References \\
\hline Stewart Island & $47^{\circ} 00^{\prime}$ & 164 & 50 & This study \\
Snares Islands & $48^{\circ} 00^{\prime}$ & 3 & 1 & Fineran (1969) \\
Auckland Islands & $50^{\circ} 40^{\prime}$ & 199 & 35 & Stephenson (2011) \\
Campbell Island & $52^{\circ} 33^{\prime}$ & 103 & 31 & Stephenson (2011) \\
Macquarie Island & $54^{\circ} 30^{\prime}$ & 409 & 25 & Stephenson et al. (2007) \\
\hline
\end{tabular}

approximately 25 percent of the 196 species recorded for all of New Zealand (Stephenson et al. 2009). However, there are relatively few regions of comparable size on either the North Island or the South Island from which more species have been reported, based on the information provided by Stephenson (2003) in his monograph on the myxomycetes of New Zealand. As part of the description of each species treated in the monograph, all of the Crosby districts from where the species in question had been recorded were listed. It is not surprising that the districts characterized by the highest numbers of species have been subjected to the most intensive collecting, as is the case for such examples as the Auckland and Dunedin districts.

It is exceedingly likely that additional collecting on Stewart Island would yield species other than those reported in this paper, but a similar statement could be made for any region of the world. However, it is interesting to note that on the basis of the data that are available for islands and island groups located south of New Zealand (Table 1), the myxomycete biota of Stewart Island conforms to the general pattern of decreasing biodiversity with increasing latitude that has been noted for many other groups of organisms (Hillebrand 2004). The single species known from the Snares Islands reflects, at least in part, the fact that no survey for myxomycetes has ever been carried out. However, because of their small size (a total land area of only about $3.5 \mathrm{~km}^{2}$ ) and relatively limited cover of vegetation, the Snares would not be expected to provide the prerequisite ecological conditions to support a diverse assemblage of myxomycetes.

The surveys carried out on Campbell Island and the Auckland Islands, as described by Stephenson (2011), also involved collections obtained in the field as well as those from moist chamber cultures. Moreover, the period of time during which each survey was carried out was relatively limited in duration, as was the case for Stewart Island. In contrast, the survey on Macquarie Island extended over a period of almost four months, and it seems likely that fewer species would have been missed.

For all three islands or island groups, the taxonomic distribution of the species present was similar in that members of the orders Physarales and Trichiales were predominant, representing $\geq 28 \%$ of the total for all species in each instance. These same two orders also contained the most species (31\% in each case) on Stewart Island.

\section{Acknowledgements}

The research reported herein was funded in part by grants from the National Science Foundation (DEB-0316284), the National Geographic Society (\#7925-05) and the New Zealand Lottery Board. Laboratory-based work in New Zealand was supported by the Foundation for Research, Science and Technology, under contract C09812. Thanks to David W. Mitchell for his comments on several of the collections from Stewart Island.

\section{References}

Fineran BA. 1969 - The flora of the Snares Islands, New Zealand. Transactions of the Royal Society of New Zealand. Botany 3, 237-270.

Hillebrand H. 2004 - On the generality of the latitudinal diversity gradient. The American Naturalist 163, 192-211.

Ing B. 1999 - The Myxomycetes of Britain and Ireland: An Identification Handbook. 
Richmond Publishing, Slough, England. Lado C. 2005-2010 - An on-line nomenclatural information system of Eumycetozoa. http://www.nomen.eumycetozoa.com accessed: 12.10.2011.

Lister A, Lister G. 1905 - Mycetozoa from New Zealand. Journal of Botany, British and Foreign 43, 111-114.

Martin GW, Alexopoulos CJ. 1969 - The Myxomycetes. University of Iowa Press, Iowa City

Mitchell DW. 1992 - The Myxomycota of New Zealand and its island territories. Nova Hedwigia 55, 231-256.

Stephenson SL. 2003 - Myxomycetes of New Zealand. Fungal Diversity Press, Hong Kong.

Stephenson SL. 2011 - Myxomycetes of the
New Zealand subantarctic islands. Sydowia 63, 215-236.

Stephenson SL, Stempen H. 1994 Myxomycetes: A Handbook of Slime Molds. Timber Press, Portland, Oregon. Stephenson SL, Laursen GA, Seppelt RD. 2007 - Myxomycetes of subantarctic Macquarie Island. Australian Journal of Botany 55, 439-449.

Stephenson SL, Novozhilov YK, Shirley C, Mitchell DW. 2009 - Additions to the myxomycetes known from New Zealand, including a new species of Diderma. Australian Systematic Botany 22, 466-472.

Wilson HD. 1994 - Stewart Island Plants. Manuka Press, Christchurch, New Zealand. 